\title{
Hyperthermia inhibits the motility of gemcitabine-resistant pancreatic cancer PANC-1 cells through the inhibition of epithelial-mesenchymal transition
}

\author{
HANGBIN JIN $^{1}$, YANYAN ZHAO ${ }^{2}$, SHIRONG ZHANG ${ }^{2}$, JIANFENG YANG ${ }^{1}$, \\ XIAOFENG ZHANG $^{1}$ and SHENGLIN MA $^{2}$ \\ Departments of ${ }^{1}$ Gastroenterology and ${ }^{2}$ Oncology, Hangzhou First People's Hospital, \\ Nanjing Medical University, Hangzhou, Zhejiang 310006, P.R. China
}

Received August 24, 2017; Accepted November 20, 2017

DOI: $10.3892 / \mathrm{mmr} .2018 .8763$

\begin{abstract}
Pancreatic cancer (PC) is one of the most common types of malignant tumor and the leading cause of cancer-associated mortality worldwide. The chemotherapeutic drug gemcitabine (GEM) is used as a first-line chemotherapeutic agent for advanced PC. However, the acquisition of drug resistance is a major limitation of the clinical effect of GEM and commonly leads to increased metastasis. The occurrence of epithelial-mesenchymal transition (EMT) has been demonstrated to be the underlying mechanism of acquired resistance. It has been reported that heat treatment is able to inhibit EMT in pancreatic adenocarcinoma cells. In the present study the effect of hyperthermia on the sensitivity of GEM-resistant PC cells was investigated. First a GEM-resistant PC cell line PANC-1 (PAN/GEM) was developed and it was demonstrated that drug resistant PAN/GEM cells exhibited significantly increased migratory and invasive abilities compared with control PANC-1 cells using a Transwell assay. EMT was induced in resistant PAN/GEM cells, followed by reduced epithelial marker epithelial (E)-cadherin expression and increased mesenchymal marker Vimentin expression compared with control PANC-1 cells. Next, the Transwell assay demonstrated that the hyperthermia at $42^{\circ} \mathrm{C}$ for $1 \mathrm{~h}$ combined with GEM significantly attenuated migration and invasion in drug resistant PAN/GEM cells, while GEM alone treatment did not significantly affect the migration and invasion. Additionally, EMT in PAN/GEM cells was reversed by hyperthermia, as demonstrated by the restoration of E-cadherin and downregulation of mesenchymal markers Vimentin, matrix metalloproteinase
\end{abstract}

Correspondence to: Dr Shenglin Ma, Department of Oncology, Hangzhou First People's Hospital, Nanjing Medical University, 261 Huansha Road, Shangcheng, Hangzhou, Zhejiang 310006, P.R. China

E-mail:mashlin@163.com

Key words: pancreatic cancer, hyperthermia, gemcitabine, migration, invasion, epithelial-mesenchymal transition
(MMP)2 and MMP9. Furthermore, an MMP2 inhibitor tissue inhibitor of metalloproteinases (TIMP)2 and MMP9 inhibitor TIMP1 were used to treat PAN/GEM cells and it was demonstrated that both inhibitors increased the inhibition of hyperthermia treatment combined with GEM on cell invasion, suggesting an association between cell invasion and MMP2, and MMP9. Additionally, proliferation of PAN/GEM cells following hyperthermia was assessed using an MTT assay. The results demonstrated that proliferation in PAN/GEM cells treated with hyperthermia was significantly inhibited by GEM compared with GEM alone treated cells, indicating that hyperthermia enhanced the inhibition of GEM on cell growth and resensitized the drug-resistant cells to GEM. Overall, the results of the present study suggested that hyperthermia is able to resensitize GEM-resistant PANC-1 cells to GEM by reversing EMT via the regulation of EMT-associated factors, therefore inhibiting cell migration and invasion.

\section{Introduction}

Pancreatic cancer (PC) is an aggressive tumor with a 7\% 5 -year survival rate worldwide $(1,2)$. Surgical resection may be the only way to cure PC. However, due to the unobservable symptoms (3), 80-95\% patients present with locally advanced or metastatic disease when diagnosed (4). Even following surgical resection of the tumor, there are still a number of patients that present relapsed or with metastatic disease $(1,5)$. Gemcitabine (GEM), a type of first-line chemotherapy for advanced $\mathrm{PC}(6,7)$, is able to induce cell apoptosis at the $\mathrm{S}$ stage of the cell cycle thereby inhibiting PC cell proliferation (8). GEM may effectively relieve symptoms of patients suffering PC. However, the therapeutic efficacy was frequently unsatisfactory for the development of drug resistance in PC cells, commonly leading to increased cell metastasis and increased therapeutic difficulty. Therefore, investigating the mechanism underlying GEM resistance and researching an effective therapy strategy to enhance the sensitivity of tumor cells to the drug is of significance for the treatment of PC.

A variety of molecular mechanisms were involved in the acquisition of drug resistance, including epithelial-mesenchymal transition (EMT) (9). EMT is a 
cellular process characterized by morphological alterations from epithelial phenotype to mesenchymal phenotype, by which cells lose epithelial cell-cell adhesion and are able to move through the extracellular matrix. EMT is frequently demonstrated to be associated with enhanced proliferation, invasion and metastasis in cancer cells (10). During EMT, cells demonstrated the acquisition of mesenchymal markers including Vimentin, type I collagen, fibronectin and Snail, and the inhibition of cell adhesion molecules including epithelial (E)-cadherin and catenin expression (11). Additionally, it has been demonstrated that EMT is correlated with chemotherapeutic sensitivity in human cancers and sensitivity to GEM in PC cells (12-14).

It has been reported that heating tumors up to a temperature of $42^{\circ} \mathrm{C}$ synergistically enhances the antitumor effect of GEM $(15,16)$, but the mechanism is not clearly known. Furthermore, hyperthermia has been demonstrated to exhibit an inhibitory effect against tumor growth factor- $\beta 1$ induced EMT (17). Therefore it was hypothesized in the present study that EMT in GEM-resistant PC cells may be suppressed by hyperthermia.

In the present study, the underlying mechanism of GEM resistance in the PC cell line PANC-1 was investigated and the effect of hyperthermia on the sensitivity and motility of GEM-resistant PANC-1 cells were analyzed. GEM-resistant PANC-1 cells were demonstrated to exhibit elevated migratory and invasive abilities. Additionally, hyperthermia combined with GEM had a synergistic inhibitory effect on cellular motility by inhibiting EMT in GEM-resistant PANC-1 cells and attenuated PC cell invasion by downregulating matrix metalloproteinase (MMP)2 and MMP9.

\section{Materials and methods}

Cell culture. The human PC cell line PANC-1 was purchased from the Type Culture Collection of the Chinese Academy of Sciences (Shanghai, China). Cells were cultured in Dulbecco's modified Eagle medium (DMEM; Gibco; Thermo Fisher Scientific, Inc., Waltham, MA, USA) supplemented with $10 \%$ fetal bovine serum (FBS; Lonza Group, Ltd., Basel, Switzerland), $5 \mathrm{mM}$ L-glutamine, $5 \mathrm{mM}$ non-essential amino acids, $100 \mathrm{U} / \mathrm{ml}$ penicillin and streptomycin (Invitrogen; Thermo Fisher Scientific, Inc.), in a humidified $5 \% \mathrm{CO}_{2}$ incubator at $37^{\circ} \mathrm{C}$. Cells were treated with hyperthermia for $1 \mathrm{~h}$ in a $42^{\circ} \mathrm{C} 5 \% \mathrm{CO}_{2}$ incubator.

Development of GEM-resistant PANC-1 cell line. GEM-resistant PANC-1 cells was developed by exposing PANC-1 cells to escalating concentrations of GEM between 0.5 and $5 \mu \mathrm{M}$ in complete medium at $37^{\circ} \mathrm{C}$ (18). Following exposure to increasing concentrations of GEM for at least 3 months until clones developed resistance to $5 \mu \mathrm{M}$ GEM, living cells were collected and called drug resistant cells (PAN/GEM), which were used for subsequent experiments.

Morphological observation of GEM-resistant cells. A total of $2 \times 10^{5}$ cells $/ \mathrm{ml}$ were cultured in $60 \mathrm{~mm}$ culture dishes for $24 \mathrm{~h}$ and then cells were treated with or without $5 \mu \mathrm{M}$ GEM for $48 \mathrm{~h}$. Medium was removed and cells were washed once with DMEM. Cell morphology was observed and images were captured using a vertical light microscope at magnification, $\mathrm{x} 100$.

Migration and invasion assay. Cell migration was assessed using a Transwell assay using $6.5 \mathrm{~mm}$ chambers (Corning Incorporated, Corning, New York, USA) with 8- $\mu \mathrm{m}$ pore membranes (19). A total of $600 \mu 1$ DMEM with GEM was added to the lower chamber. The suspension of $5 \times 10^{4}$ cells in $100 \mu \mathrm{l}$ DMEM with $1 \%$ FBS was plated into the upper chamber following by adding GEM. After $20 \mathrm{~h}$, cells on the undersurface of the polycarbonate membranes were stained with crystal violet (Amresco, Inc., Framingham, MA, USA) for $10 \mathrm{~min}$ at room temperature and were observed using a light microscope at magnification, $\mathrm{x} 100$, and six fields were chosen at random to measure the average cell coverage using Image J software (version 1.47; National Institutes of Health, Bethesda, MD, USA). Relative migratory cell number was expressed as a percentage of the control. Invasion was assayed using the same procedure as the migration assay, except that $70 \mu 11 \mathrm{mg} / \mathrm{ml}$ Matrigel (BD Biosciences, San Jose, CA, USA) was added into the upper surface of the membrane.

Western blot analysis. Cells were washed twice with PBS and extracted using Mammalian Protein Extraction reagent (Pierce; Thermo Fisher Scientific, Inc.) according to the manufacturer's protocol. The proteins $(50 \mu \mathrm{g})$ were separated by $10 \%$ SDS-PAGE (Beijing Solarbio Science \& Technology Co., Ltd., Beijing, China) and transferred to polyvinylidene fluoride membranes (EMD Millipore, Billerica, MA, USA). The membranes were blocked with 5\% non-fat dried milk in TBST for $1 \mathrm{~h}$ at room temperature and incubated with specific primary antibodies overnight at $4^{\circ} \mathrm{C}$ : Mouse monoclonal anti-E-cadherin (cat. no. sc-21791; 1:2,000; Santa Cruz Biotechnology, Inc., Dallas, TX, USA), mouse monoclonal anti-Vimentin (cat. no. sc-6260; 1:2,000; Santa Cruz Biotechnology, Inc.), mouse monoclonal anti- $\beta$-actin (cat. no. sc47778; 1:1,000; Santa Cruz Biotechnology, Inc.), rabbit polyclonal anti-MMP2 antibody (cat. no. 4022; 1:1,000; Cell Signaling Technology, Inc., Danvers, MA, USA), rabbit polyclonal anti-MMP9 antibody (cat. no. 3852; 1:1,000; Cell Signaling Technology, Inc.) were used, followed by horseradish peroxidase-conjugated secondary antibodies goat anti-mouse (cat. no. sc-2005; 1:2,000; Santa Cruz Biotechnology, Inc.) and goat anti-rabbit (cat. no. sc-2004; 1:2,000; Santa Cruz Biotechnology, Inc.) IgG secondary antibodies for $2 \mathrm{~h}$ at room temperature. Development was performed using enhanced chemiluminescence-detecting reagent (GE Healthcare, Chicago, IL, USA).

Reverse-transcription-quantitative polymerase chain reaction $(R T-q P C R)$. Total RNA in cells was extracted using a total RNA mini plus kit (A\&A Biotechnology, Gdynia, Poland). cDNA was obtained by RT-PCR using a RevertAid ${ }^{\mathrm{TM}}$ First Strand cDNA synthesis kit (Fermentas; Thermo Fisher Scientific, Inc., Pittsburgh, PA, USA) in a $50 \mu$ l reaction mixture. Reverse transcription was carried out at $45^{\circ} \mathrm{C}$ for 45 min. cDNA was subsequently amplified using TaqMan ${ }^{\circledR}$ Gene Expression assay (Applied Biosystems; Thermo Fisher Scientific, Inc.). The PCR thermocycling conditions were as follows: Initial denaturation at $94^{\circ} \mathrm{C}$ for $3 \mathrm{~min}, 40$ amplification 
cycles of $94^{\circ} \mathrm{C}$ for $10 \mathrm{sec}, 53^{\circ} \mathrm{C}$ for $30 \mathrm{sec}$ and $72^{\circ} \mathrm{C}$ for $40 \mathrm{sec}$, followed by a final extension at $72^{\circ} \mathrm{C}$ for $10 \mathrm{~min}$. The primers were as follows: E-cadherin forward (F), 5'-GTCAGTTCA GACTCCAGCCC-3' and reverse (R), 5'-AAATTCACTCTG CCCAGGACG-3'; Vimentin F, 5'-TCTACGAGGAGGAGA TGCGG-3' and R, 5'-GGTCAAGACGTGCCAGAGAC-3'; MMP2 F, 5'-TATGGCTTCTGCCCTGAGAC-3' and R, 5'-CACACCACATCTTTCCGTCA-3'; MMP9 F, 5'-AGTCCA CCCTTGTGCTCTTC-3' and R, 5'-ACTCTCCACGCATCT CTGC-3'; GAPDH F, 5'-GATCCCTCCAAAATCAAGTG-3' and R, 5'-GAGTCCTTCCACGATACCAA-3'. RT-qPCR was performed using ABI PRISM 7,700 Sequence detector (Applied Biosystems; Thermo Fisher Scientific, Inc.) with SDS software version 1.7. mRNA expression of target genes was calculated using the formula $2^{-\Delta \Delta \mathrm{Cq}}(20)$ and was normalized to the level of GAPDH. The value of mRNA in cells was demonstrated as the relative value of mRNA in control cells.

Cytotoxicity assay. The cytotoxicity of GEM on cells was evaluated using an MTT assay (Sigma Aldrich; Merck $\mathrm{KGaA}$, Darmstadt, Germany). A total of $1 \times 10^{4}$ cells were seeded into each well of a 96-well plate in $100 \mu 1$ medium and incubated with various concentration of GEM for $48 \mathrm{~h}$ at $37^{\circ} \mathrm{C}$ in a $5 \% \mathrm{CO}_{2}$ incubator. Then cells were incubated with $20 \mu \mathrm{l} 5 \mathrm{mg} / \mathrm{ml} \mathrm{MTT}$ for $4 \mathrm{~h}$ at $37^{\circ} \mathrm{C}$ and then cells were lysed for $10 \mathrm{~min}$ at room temperature by addition of $200 \mu \mathrm{l}$ dimethyl sulfoxide (OriGen Biomedical, Inc., Austin, TX, USA). Absorbance was measured at $490 \mathrm{~nm}$ using a microplate reader. Cell survival was expressed as a percentage of the untreated control.

Metalloproteinase inhibitor (TIMP)1 and TIMP2 adenoviral infection of PANC-1 cell line. Human TIMP1 and TIMP2 cDNA plasmids were obtained from Wuhan Huamei Bioengineering Co., Ltd. (Wuhan, China). The adenovirus serotype 2 vector system with Adßgal was obtained from Genzyme (Framingham, MA, USA). The TIMP adenovirus vectors were constructed as previously described (21). Briefly, the titer of the recombinant adenoviral vectors was established by the logarithmic limiting dilution in 293 cells. The lowest dilution at which CPE occurred was taken to be the titer of the virus. Adenoviral stocks were screened for replication-competent adenovirus by titration in non-permissive PANC-1 cells (21-23). Cells $\left(1 \times 10^{5}\right)$ were infected with Ad $\beta$ gal virus at multiplicities of infection of $10,50,100$, 500 and 1,000 in the presence of 2\% FCS (Lanzhou Minhai Bioengineering Co., Ltd., Lanzhou, China) for $18 \mathrm{~h}$ at $37^{\circ} \mathrm{C}$ using Lipofectamine ${ }^{\circledR} 2000$ (Invitrogen; Thermo Fisher Scientific, Inc.) according to the manufacturer's instructions. The medium was subsequently removed and replaced with fresh medium plus 10\% FCS. Cells were washed with PBS and used for subsequent experimentation after $24 \mathrm{~h}$.

Statistical analysis. Data were obtained from at least three experiments. Statistical analysis was preformed using SPSS 13.0 (SPSS, Inc., Chicago, IL, USA). Values are presented as the mean \pm standard error of the mean. One-way analysis of variance was used to assess differences between groups. The Duncan's new multiple range test was subsequently employed for pairwise comparisons followed by the Bonferroni correction. $\mathrm{P}<0.05$ was considered to indicate a statistically significant difference.

\section{Results}

$E M T$ is involved in the development of GEM-resistant PC PANC-1 cells. To investigate the mechanism underlying GEM resistance in PC, a GEM-resistant PC PANC-1 cell model (PAN/GEM) was first constructed. PAN/GEM cells were developed by exposing PANC-1 cells to escalating concentrations of GEM in complete medium and evaluating which cells demonstrated resistance to GEM. It was observed that PAN/GEM cells grew faster compared with PANC1 cells in medium without GEM (data not shown). The cytotoxicity of GEM on PAN/GEM and PANC-1 cells was evaluated by analyzing cell growth using an MTT assay. The $\mathrm{IC}_{50}$ of GEM was determined by exposing PAN/GEM and PANC-1 cells to different concentrations of GEM for $48 \mathrm{~h}$. IC $_{50}$ values of the two cell lines were respectively calculated to be 29.3 and $5.1 \mathrm{mmol} / \mathrm{l}$ (Fig. 1A). Furthermore, it was demonstrated that GEM-resistant PAN/GEM cells exhibited EMT phenotypes characterized by spindle-like morphology (Fig. 1B). The two cell types were treated with $5 \mu \mathrm{M}$ GEM for $48 \mathrm{~h}$ and prior to visualizing their morphology. As expected, PANC-1 cells were rounded and exhibited membrane blebbing, which is an apoptotic feature. However, no significant alterations in PAN/GEM morphology were observed (Fig. 1B). Additionally, it was demonstrated that migration and invasion rates in GEM-resistant PAN/GEM cells were significantly increased $(\mathrm{P}<0.01$; Fig. $1 \mathrm{C}$ and $\mathrm{D})$. This was accompanied by significantly decreased E-cadherin and increased Vimentin expression $(\mathrm{P}<0.01$; Fig. 1E), compared with PANC-1 cells, suggesting that EMT was involved in the development of GEM resistance in PANC-1 cells, and the enhancement of cellular motility.

Hyperthermia combined with GEM attenuates migration and invasion in GEM-resistant PAN/GEM cells. To investigate the effect of hyperthermia on migration and invasion of GEM-resistant PAN/GEM cells, PC cells were treated with hyperthermia at $42^{\circ} \mathrm{C}$ for $1 \mathrm{~h}$ and then treated with $5 \mu \mathrm{M}$ GEM for $24 \mathrm{~h}$. Transwell assays demonstrated that hyperthermia combined with GEM significantly decreased the migration and invasion in PAN/GEM cells compared with the GEM treatment alone $(\mathrm{P}<0.01)$, while GEM alone treatment did not significantly affect the migration and invasion compared with untreated control group (Fig. 2A and B). These data implicated that hyperthermia combined with GEM was able to effectively eliminate cellular resistance to GEM by inhibiting migration and invasion.

Hyperthermia reverses EMT in GEM-resistant PAN/GEM cells. To investigate the underlying mechanism of hyperthermia inhibiting migration and invasion of GEM-resistant PAN/GEM cells, cells were treated with hyperthermia at $42^{\circ} \mathrm{C}$ for $1 \mathrm{~h}$, and then treated with $5 \mu \mathrm{M}$ GEM for $48 \mathrm{~h}$. EMT molecular markers were detected by RT-qPCR and western blot analysis. The results demonstrated that GEM treatment alone did not significantly alter the expression of E-cadherin, Vimentin, MMP2/9 compared with untreated PAN/GEM cells, while hyperthermia treatment alone at $42^{\circ} \mathrm{C}$ slightly increased E-cadherin expression, and decreased Vimentin and 
A

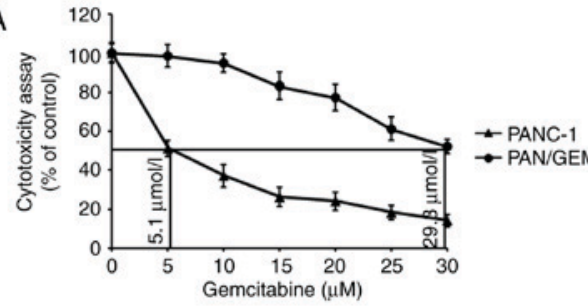

C
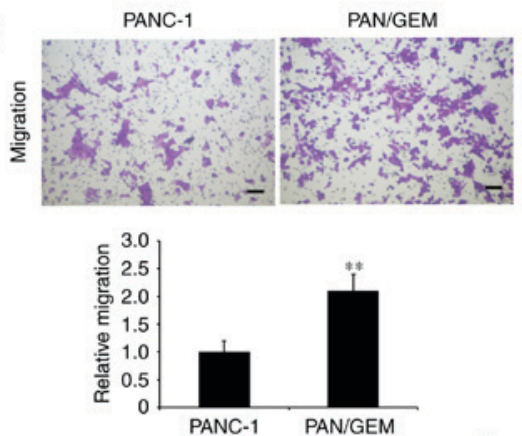

$E_{\text {PANC-1 PAN/GEM }}$

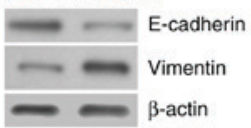

B

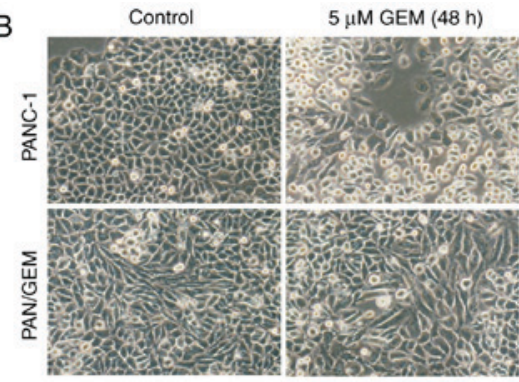

D

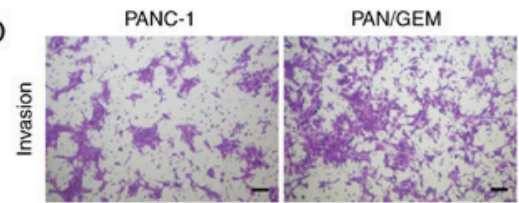

Figure 1. Characterization of PAN/GEM and PANC-1 cells. (A) The cytotoxicity of GEM on cells was evaluated using a MTT assay. Cells were incubated in $100 \mu \mathrm{l}$ medium for $24 \mathrm{~h}$, and then were treated with $0,5,10,15,20,25$ and $30 \mu \mathrm{M}$ GEM for $48 \mathrm{~h}$. The $\mathrm{IC}_{50}$ values of the two cells were calculated. The cytotoxicity was expressed as a percentage of GEM-untreated control. (B) PAN/GEM and PANC-1 cells were exposed to $5 \mu \mathrm{M}$ GEM for $48 \mathrm{~h}$ and then the morphology was visualized using a vertical microscope (magnification, x100). (C) Cell migration and (D) invasion were assessed using a Transwell assay. PAN/GEM cells demonstrated an increased migratory and invasive ability compared to PANC-1 cells. Migratory and invasive cells on the undersurface of the polycarbonate membranes were observed using a light microscope (magnification, x100). Scale bar=100 $\mu \mathrm{m}$. (E) E-cadherin and Vimentin expression in PAN/GEM and PANC-1 cells were assessed by western blot analysis using an anti-E-cadherin or anti-Vimentin antibody. $\beta$-actin was detected as an internal standard. The protein blots were quantified by densitometry and the amounts were expressed relative to the internal reference $\beta$-actin. ${ }^{* *} \mathrm{P}<0.01$ vs. PANC-1 cells. PAN/GEM, gemcitabine-resistant pancreatic cancer cell line PANC-1; E, epithelial.

A

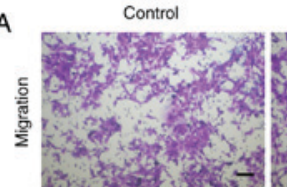

$42^{\circ} \mathrm{C}$

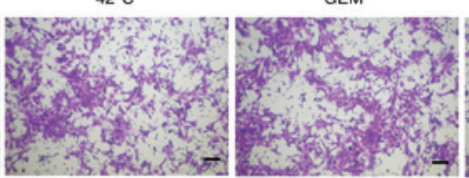

NS

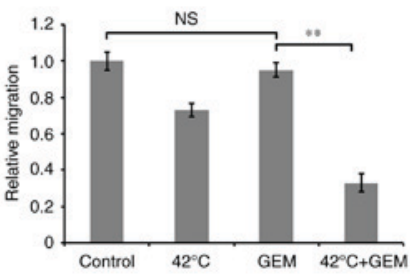

B

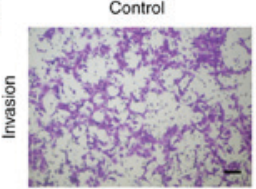

$42^{\circ} \mathrm{C}$
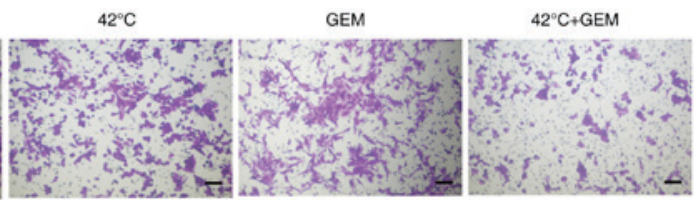

$42^{\circ} \mathrm{C}+\mathrm{GEM}$
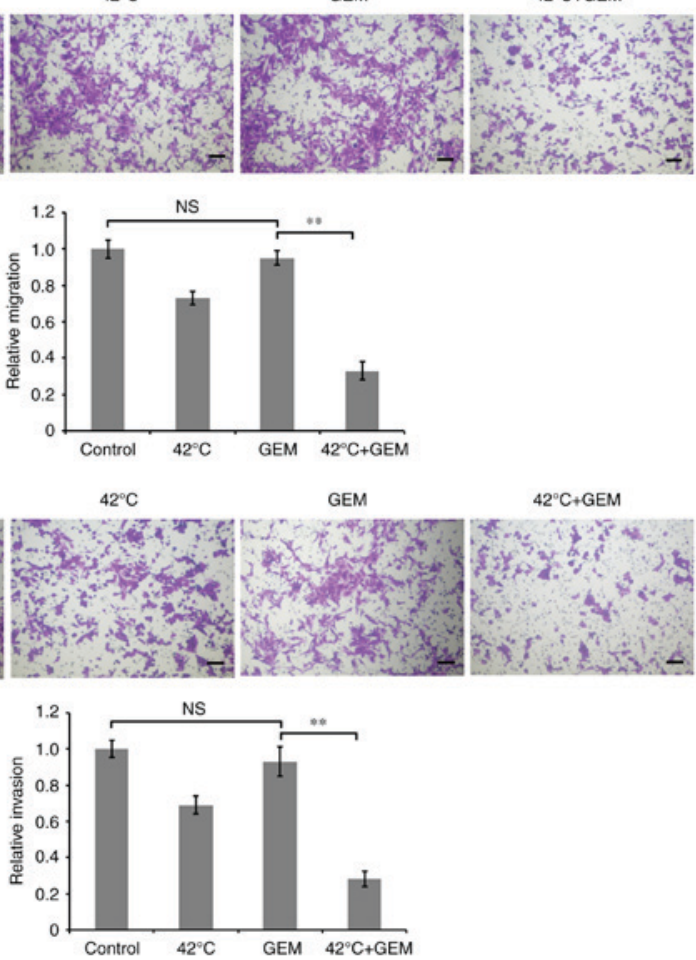

Figure 2. Effect of hyperthermia on migration and invasion in PAN/GEM cells. PAN/GEM cells were treated with or without hyperthermia at $42^{\circ} \mathrm{C}$ for $1 \mathrm{~h}$ and then treated with $5 \mu \mathrm{M}$ GEM for $24 \mathrm{~h}$. (A) Cell migration and (B) invasion were evaluated using a Transwell assay. Migratory and invasive cells on the undersurface of the polycarbonate membranes were observed by a light microscope (magnification, $\mathrm{x} 100$ ). Scale bar=100 $\mu \mathrm{m}$. ${ }^{* *} \mathrm{P}<0.01 ; \mathrm{N} . \mathrm{S}$., no significance; PAN/GEM, gemcitabine-resistant pancreatic cancer cell line PANC-1. 

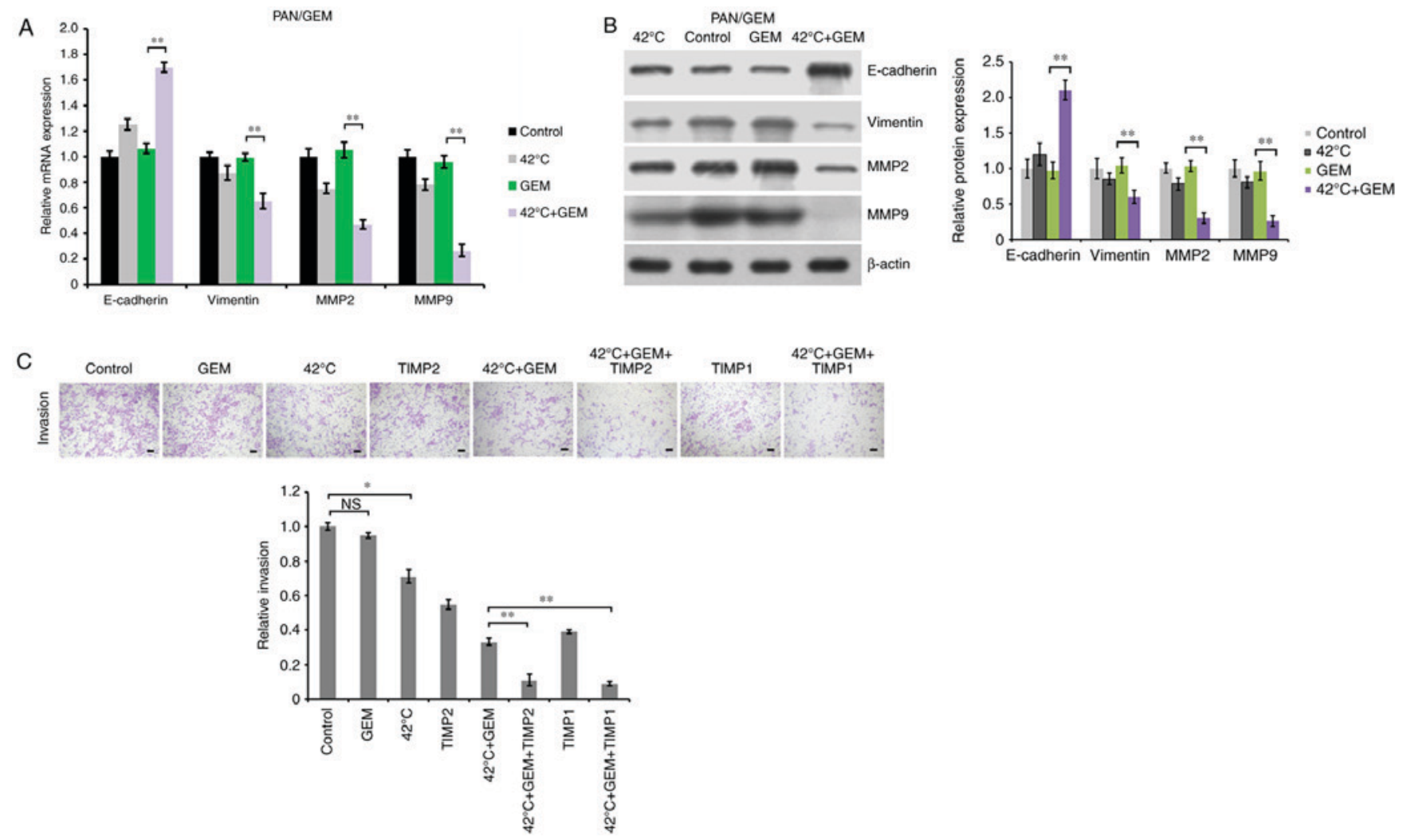

Figure 3. Hyperthermia reverses EMT-associated markers expression in GEM-resistant PAN/GEM cells. PAN/GEM cells were treated with or without hyperthermia at $42^{\circ} \mathrm{C}$ for $1 \mathrm{~h}$ and then treated with $5 \mu \mathrm{M}$ GEM for $48 \mathrm{~h}$. (A) The mRNA expression levels of EMT molecular markers E-cadherin, Vimentin, MMP2 and MMP9 were detected by reverse transcription-quantitative polymerase chain reaction and (B) the protein expression levels were detected by western blot analysis using their specific antibodies. $\beta$-actin was detected as an internal reference. The protein blots were quantified by densitometry and the amounts were expressed relative to the internal reference $\beta$-actin. (C) PAN/GEM cells were infected with or without an adenovirus Adßgal expressing TIMP2 or TIMP1 for $24 \mathrm{~h}$ and then were treated with hyperthermia at $42^{\circ} \mathrm{C}$ for $1 \mathrm{~h}$, followed by treatment with $5 \mu \mathrm{M}$ GEM for $24 \mathrm{~h}$. Cell invasion was evaluated using a Transwell assay. Scale bar $=100 \mu \mathrm{m} .{ }^{*} \mathrm{P}<0.05 ;{ }^{* *} \mathrm{P}<0.01$; N.S., no significance; PAN/GEM, gemcitabine-resistant pancreatic cancer cell line PANC-1; MMP, matrix metalloproteinase; TIMP, tissue inhibitor metalloproteinase; EMT, epithelial mesenchymal transition.

MMP2/9 expression (Fig. 3A and B). It was demonstrated that hyperthermia combined with GEM significantly upregulated E-cadherin, and downregulated Vimentin, MMP2 and MMP9 at the mRNA and protein levels to reverse EMT compared with the GEM treatment alone $(\mathrm{P}<0.01$; Fig. $3 \mathrm{~A}$ and $\mathrm{B})$. These findings identified that hyperthermia at $42^{\circ} \mathrm{C}$ was able to reverse EMT to mesenchymal-epithelial transition in PAN/GEM cells, which may imply a mechanism for the effect of hyperthermia combined with GEM on PC cell migration and invasion. MMP2 and MMP9 have been demonstrated to be overexpressed in a number of aggressive tumors, and to be associated with tumor invasion (24). To confirm the mechanism underlying hyperthermia combined with GEM inhibiting PC cell invasion, TIMP1 and TIMP2 were introduced to inhibit their catalytic activity by adenovirus Ad $\beta$ gal expressing TIMP1 or TIMP2 infection (21). Following infection for $24 \mathrm{~h}$, cell invasion was evaluated. The data demonstrated that TIMP2 and TIMP1 significantly augmented the inhibition of hyperthermia plus GEM on cell invasion $(\mathrm{P}<0.01$; Fig. $3 \mathrm{C})$. The inhibitory effect of TIMP1 and TIMP2 on MMP2/9 was confirmed by MMP2/9 activity detection using MMP2/9 activity assay kit (gelatin zymography) (data not shown). These results suggest that hyperthermia plus GEM may attenuate PC cell invasion by downregulating MMP2 and MMP9.
Hyperthermia enhances sensitivity of GEM-resistant PAN/GEM cells to GEM. To determine whether hyperthermia increases the sensitivity of PAN/GEM cells to GEM, an MTT assay on PAN/GEM cells treated with or without hyperthermia was performed. It was demonstrated that hyperthermia significantly enhanced cell growth inhibition induced by $5 \mu \mathrm{M}$ GEM in PAN/GEM cells, while hyperthermia or GEM alone treatment did not significantly affect cell proliferation compared with the control $(\mathrm{P}<0.01$; Fig. 4). These data indicated that PAN/GEM cells with hyperthermia treatment exhibited markedly increased sensitivity to GEM compared with without hyperthermia treatment.

\section{Discussion}

$\mathrm{PC}$ is an aggressive disease and a major cause of cancer-associated mortality with the 5-year survival rate being $<10 \%$ worldwide $(1,25)$. It has been demonstrated that $\sim 80-95 \%$ of patients are at the locally advanced or metastatic disease stage when diagnosed (4) due to the unobservable symptoms of PC (3). Thus, there is a need to identify strategies to treat and manage PC. GEM is one of the chemotherapeutic agents used to treat advanced PC. However, nearly all patients eventually succumb to relapse due to drug resistance, thus making the therapeutic efficacy of GEM significantly limited. Therefore, 
A

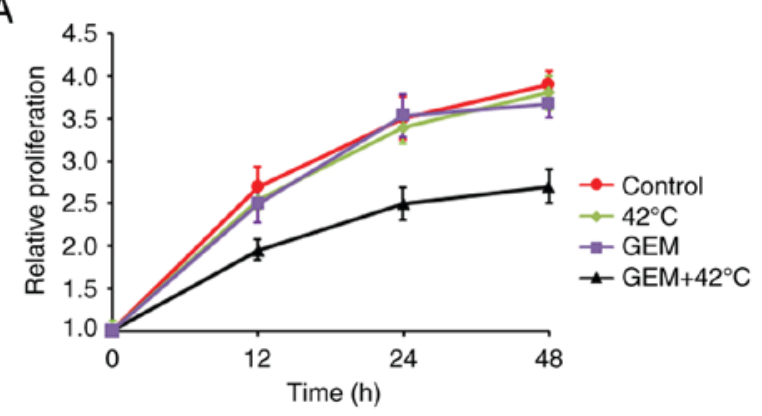

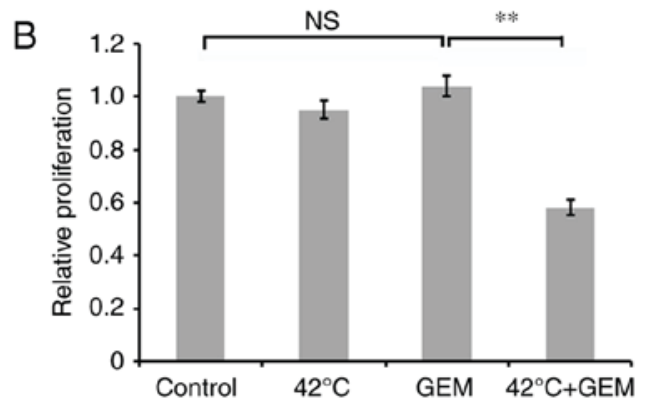

Figure 4. Hyperthermia enhances GEM inhibition of proliferation of PAN/GEM cells. PAN/GEM cells were treated with or without hyperthermia at $42^{\circ} \mathrm{C}$ for $1 \mathrm{~h}$ and then treated with or without $5 \mu \mathrm{M}$ GEM for 12, 24, and $48 \mathrm{~h}$. (A) Cell proliferation was assessed using a MTT assay and growth curve were drawn. (B) PAN/GEM cells were treated with or without hyperthermia at $42^{\circ} \mathrm{C}$ for $1 \mathrm{~h}$ and then treated with or without $5 \mu \mathrm{M}$ GEM for $48 \mathrm{~h}$. Cell proliferation was assessed using a MTT assay. ${ }^{* *} \mathrm{P}<0.01$; N.S., no significance; PAN/GEM, gemcitabine-resistant pancreatic cancer cell line PANC-1.

investigating effective therapeutic strategies are necessary to overcome the acquisition of drug resistance. In the present study it was demonstrated that hyperthermia was able to attenuate the drug resistance of PC PANC-1 cells to GEM, and hyperthermia in combination with GEM was able to inhibit cell migration and invasion through EMT inhibition.

In the present study, a GEM-resistant PC cell line, PAN/GEM, was developed by simulating the condition of drug resistance development in vivo using increasing concentrations of GEM. The cell proliferation assay demonstrated that the $\mathrm{IC}_{50}$ of GEM in drug-resistant PAN/GEM cells at $48 \mathrm{~h}$ was significantly increased compared with the parental PANC-1 cells. GEM at $5 \mu \mathrm{M}$ did not significantly affect the proliferation of PAN/GEM cells, while under identical conditions, the proliferation of parental PANC-1 cells was reduced by $\sim 50 \%$, suggesting that PAN/GEM cells demonstrated the resistance to GEM and could be used in subsequent experiments. In addition, it was demonstrated that generation of GEM resistance caused the alteration of PANC-1 cell morphology transforming from cobblestone-like epithelial cells into slender spindle-shaped cells, suggesting the occurrence of the EMT phenotype in resistant cells. In addition, EMT is characterized by the loss of cell adhesion molecules, including E-cadherin and elevation of mesenchymal markers such as Vimentin (11). It was demonstrated that that GEM-resistant PAN/GEM cells exhibited significant downregulation of E-cadherin expression and upregulation of Vimentin expression compared with parental PANC-1 cells. These data supported that the development of PANC-1 cells resistant to GEM induced EMT. A previous study indicated that EMT was involved in the acquisition of drug resistance (9). Therefore, in the present study it was hypothesized that EMT may be the mechanism underlying the acquisition of GEM resistance in PANC-1 cells.

It has been reported that heating tumors may synergistically enhance antitumor effect of GEM $(15,26)$ and that hyperthermia exhibits an inhibitory effect on EMT (17). Thus, PC cells were treated with different temperatures for different durations and the optimized temperature at $42^{\circ} \mathrm{C}$ for $1 \mathrm{~h}$ was chosen (data not shown). Under these conditions, hyperthermia treatment alone did not significantly affect cell proliferation and minimized cytotoxicity. Additionally, it was demonstrated that the temperature of $42^{\circ} \mathrm{C}$ was able to effectively enhance the effect of GEM on inhibiting PC cell migration and invasion.
E-cadherin has been identified as a tumor suppressor in multiple cancer types (27), and has been demonstrated to serve a role in limiting cell motility and migration (28). In the present study, the expression level of E-cadherin was analyzed at the mRNA and protein levels. When treated with hyperthermia plus GEM, PC PANC-1 cells demonstrated significantly increased E-cadherin expression, implying that hyperthermia plus GEM may affect PC cell migration by upregulating E-cadherin. MMPs are a family of zinc-dependent endopeptidases (29). MMP2 and MMP9 are family members of MMPs, and facilitate the invasion of cancer cells $(30,31)$. MMP2 and MMP9 expression are associated with various morphological features in pancreatic ductal adenocarcinoma (32). A previous study reported that MMP2 was involved in promoting invasion of hepatocellular carcinoma cells (31). Furthermore, hyperthermia has been reported to be able to inhibit cell metastases and downregulate the expression of cancer metastasis associated genes, including membrane type 1-matrix metalloproteinase, which is a known activator of latent MMP2 (33). In the present study, it was demonstrated that hyperthermia at $42^{\circ} \mathrm{C}$ significantly decreased cell migration and invasion in resistant PAN/GEM cells, and then the expression levels of MMP2 and MMP9 in PANC-1/GEM cells following treated with hyperthermia plus GEM were analyzed. The results demonstrated a significant decrease in MMP2 and MMP9 expression at the mRNA and protein levels in PANC-1/GEM cells treated with hyperthermia plus GEM compared with GEM treatment alone. It suggested that hyperthermia combined with GEM affected PC cell invasion through downregulating MMP2 and MMP9. TIMP is an inhibitor of MMPs, which binds $\mathrm{Zn}^{2+}$ at the active site of MMPs to block catalytic activity (34). MMP2 and MMP9 inhibitors, TIMP2 and TIMP1 were used in the present study to inhibit MMP activity. The inhibitory effect of TIMP1 and TIMP2 on MMP2/9 was confirmed by MMP2/9 activity detection using MMP2/9 activity assay kit (gelatin zymography; data not shown). TIMP2 and TIMP1 enhanced the suppression of hyperthermia plus GEM on the invasion of PC cells even if hyperthermia combined with GEM itself could suppress the invasion of PC cells. Therefore, the present study demonstrated that hyperthermia combined with GEM probably affected GEM-resistant PC PANC-1 cell invasion by downregulating MMP2 and MMP9. 
In conclusion, the results of the present study demonstrated that hyperthermia at $42^{\circ} \mathrm{C}$ combined with GEM may be a more effective way for improving the sensitivity of PC PANC-1 cells to GEM and inhibiting cell invasion by reversing EMT. The present study may provide a promising clinical therapeutic strategy for PC. To verify the universality of the therapeutic strategy in PC, additional PC cell lines are required to complete the present study.

\section{References}

1. Worni M, Guller U, White RR, Castleberry AW, Pietrobon R, Cerny T, Gloor B and Koeberle D: Modest improvement in overall survival for patients with metastatic pancreatic cancer: A trend analysis using the surveillance, epidemiology, and end results registry from 1988 to 2008. Pancreas 42: 1157-1163, 2013

2. Siegel RL, Miller KD and Jemal A: Cancer statistics, 2016. CA Cancer J Clin 66: 7-30, 2016

3. Bednar F and Simeone DM: Recent advances in pancreatic surgery. Curr Opin Gastroenterol 30: 518-523, 2014.

4. Ottaiano A, Capozzi M, De Divitiis C, De Stefano A, Botti G, Avallone A and Tafuto S: Gemcitabine mono-therapy versus gemcitabine plus targeted therapy in advanced pancreatic cancer: A meta-analysis of randomized phase III trials. Acta Oncol 56 377-383, 2017.

5. Ghaneh P,Smith R, Tudor-Smith C, Raraty M and Neoptolemos JP: Neoadjuvant and adjuvant strategies for pancreatic cancer. Eur J Surg Oncol 34: 297-305, 2008.

6. Massari F, Santoni M, Ciccarese C, Brunelli M, Conti A, Santini D, Montironi R, Cascinu S and Tortora G: Emerging concepts on drug resistance in bladder cancer: Implications for future strategies. Crit Rev Oncol Hematol 96: 81-90, 2015.

7. de Sousa Cavalcante L and Monteiro G: Gemcitabine: Metabolism and molecular mechanisms of action, sensitivity and chemoresistance in pancreatic cancer. Eur J Pharmacol 741: 8-16, 2014.

8. Miao X, Koch G, Ait-Oudhia S, Straubinger RM and Jusko WJ: Pharmacodynamic modeling of cell cycle effects for gemcitabine and trabectedin combinations in pancreatic cancer cells. Front Pharmacol 7: 421, 2016.

9. Wu P, Zhu Y, Yang C, Wang Y and Wang G; Department of oncology, huangshan people's hospital, affiliated to wangnan medical college: The mechanism and countermeasures on the secondary resistance of epidermal growth factor receptor tyrosine kinase inhibitor (EGFR-TKI). Anti-Tumor Pharm 5: 4, 2015.

10. Thiery JP, Acloque H, Huang RY and Nieto MA: Epithelial-mesenchymal transitions in development and disease. Cell 139: 871-890, 2009.

11. Robert G, Gaggioli C, Bailet O, Chavey C, Abbe P, Aberdam E, Sabatié E, Cano A, Garcia de Herreros A, Ballotti R and Tartare-Deckert S: SPARC represses E-cadherin and induces mesenchymal transition during melanoma development. Cancer Res 66: 7516-7523, 2006.

12. Voulgari A and Pintzas A: Epithelial-mesenchymal transition in cancer metastasis: Mechanisms, markers and strategies to overcome drug resistance in the clinic. Biochim Biophys Acta 1796: 75-90, 2009.

13. Neel DS and Bivona TG: Secrets of drug resistance in NSCLC exposed by new molecular definition of EMT. Clin Cancer Res 19: 3-5, 2013.

14. Ma J, Fang B, Zeng F, Ma C, Pang H, Cheng L, Shi Y, Wang H, Yin B, Xia J and Wang Z: Down-regulation of miR-223 reverses epithelial-mesenchymal transition in gemcitabine-resistant pancreatic cancer cells. Oncotarget 6: 1740-1749, 2015.

15. Maeda H, Wu J, Sawa T, Matsumura Y and Hori K: Tumor vascular permeability and the EPR effect in macromolecular therapeutics: A review. J Control Release 65: 271-284, 2000.
16. Kirui DK, Celia C, Molinaro R, Bansal SS, Cosco D, Fresta M, Shen $\mathrm{H}$ and Ferrari M: Mild hyperthermia enhances transport of liposomal gemcitabine and improves in vivo therapeutic response. Adv Healthc Mater 4: 1092-1103, 2015.

17. Kimura-Tsuchiya R, Ishikawa T, Kokura S, Mizushima K, Adachi S, Okajima M, Matsuyama T, Okayama T, Sakamoto N, Katada K, et al: The inhibitory effect of heat treatment against epithelial-mesenchymal transition (EMT) in human pancreatic adenocarcinoma cell lines. J Clin Biochem Nutr 55: 56-61, 2014

18. Meena AS, Sharma A, Kumari R, Mohammad N, Singh SV and Bhat MK: Inherent and acquired resistance to paclitaxel in hepatocellular carcinoma: Molecular events involved. PLoS One 8: e61524, 2013.

19. Gu Y, Zhang J, Mi W, Yang J, Han F, Lu X and Yu W: Silencing of GM3 synthase suppresses lung metastasis of murine breast cancer cells. Breast Cancer Res 10: R1, 2008

20. Livak KJ and Schmittgen TD: Analysis of relative gene expression data using real-time quantitative PCR and the 2(-Delta Delta C(T)) method. Methods 25: 402-408, 2001.

21. Rigg AS and Lemoine NR: Adenoviral delivery of TIMP1 or TIMP2 can modify the invasive behavior of pancreatic cancer and can have a significant antitumor effect in vivo. Cancer Gene Ther 8: 869-878, 2001.

22. Gerald R and Meidel RS: Adenoviral vectors. In: Glover DM, Hames BD (eds). DNA Cloning 4. A Prac Appr. Oxford Univ Press, Oxford: pp 285-305, 1996.

23. Mittereder N, March KL and Trapnell BC: Evaluation of the concentration and bioactivity of adenovirus vectors for gene therapy. J Virol 70: 7498-7509, 1996.

24. Sun XF, Shao YB, Liu MG, Chen Q, Liu ZJ, Xu B, Luo SX and Liu H: High-concentration glucose enhances invasion in invasive ductal breast carcinoma by promoting Glut1/MMP2/MMP9 axis expression. Oncol Lett 13: 2989-2995, 2017.

25. Ferlay J, Shin HR, Bray F, Forman D, Mathers C and Parkin DM: Estimates of worldwide burden of cancer in 2008: GLOBOCAN 2008. Int J Cancer 127: 2893-2917, 2010.

26. Kim CE, Lim SK and Kim JS: In vivo antitumor effect of cromolyn in PEGylated liposomes for pancreatic cancer. J Control Release 157: 190-195, 2012.

27. Shamir ER and Ewald AJ: Adhesion in mammary development: Novel roles for E-cadherin in individual and collective cell migration. Curr Top Dev Biol 112: 353-382, 2015.

28. Kowalski PJ, Rubin MA and Kleer CG: E-cadherin expression in primary carcinomas of the breast and its distant metastases. Breast Cancer Res 5: R217-R222, 2003

29. Baruch RR, Melinscak H, Lo J, Liu Y, Yeung O and Hurta RA: Altered matrix metalloproteinase expression associated with oncogene-mediated cellular transformation and metastasis formation. Cell Biol Int 25: 411-420, 2001

30. Jacob A and Prekeris R: The regulation of MMP targeting to invadopodia during cancer metastasis. Fron Cell Dev Biol 3: 4, 2015.

31. Chen Y, Yu Y, Sun S, Wang Z, Liu P, Liu S and Jiang J: Bradykinin promotes migration and invasion of hepatocellular carcinoma cells through TRPM7 and MMP2. Exp Cell Res 349: 68-76, 2016.

32. Jakubowska K, Pryczynicz A, Januszewska J, Sidorkiewicz I, Kemona A, Niewiński A, Lewczuk Ł, Kedra B and Guzińska-Ustymowicz K: Expressions of matrix metalloproteinases 2, 7 and 9 in carcinogenesis of pancreatic ductal adenocarcinoma. Dis Markers 2016: 9895721, 2016.

33. Sawaji Y, Sato T, Seiki M and Ito A: Heat shock-mediated transient increase in intracellular 3',5'-cyclic AMP results in tumor specific suppression of membrane type 1-matrix metalloproteinase production and progelatinase A activation. Clin Exp Metastasis 18: 131-138, 2000.

34. Sternlicht MD and Werb Z: How matrix metalloproteinases regulate cell behavior. Annu Rev Cell Dev Biol 17: 463-516, 2001. 